\title{
Avaliação da influência do infravermelho e da diatermia por microondas associados ao alongamento passivo no encurtamento dos músculos isquiotibiais
}

\author{
Aline Simões de Alencastro ${ }^{1}$ \\ Flávia Ladeira Ventura Dumas²
}

\section{Resumo}

A diatermia por microondas é uma modalidade de aquecimento profundo, e a radiação infravermelha aquece praticamente a epiderme. Em algumas práticas clínicas, para se obter um maior ganho da flexibilidade usam-se técnicas de alongamento associadas ao calor. Este estudo teve como objetivo verificar a influência e as diferenças na utilização dos recursos térmicos de calor profundo e superficial na flexibilidade da musculatura isquiotibial. Dezenove estudantes do Curso de Fisioterapia do Centro Universitário de Brasília foram distribuídos em três grupos distintos de forma aleatória: GC (alongamento muscular passivo), GCS (infravermelho associado ao alongamento passivo) e GCP (diatermia por microondas associada ao alongamento). Os resultados foram obtidos por meio da analise do ângulo poplíteo antes e depois de cada intervenção, relacionando o recurso com o alongamento. Concluiu-se que a aplicação da termoterapia profunda ou superficial auxilia no alongamento da musculatura isquiotibial.

Palavras-chave: Termoterapia superficial. Termoterapia profunda. Alongamento. Isquiotibiais.

\footnotetext{
${ }^{1}$ Programa de Iniciação Científica do UniCEUB - graduanda de fisioterapia.

${ }^{2}$ Graduação em Fisioterapia pela Universidade Católica de Brasília (2002) e mestrado em Engenharia Biomédica pela Universidade do Vale do Paraíba (2004). Professora do Centro Universitário de Brasília e fisioterapeuta da Secretaria de Saúde do Distrito Federal.
} 


\section{Introdução}

Contração muscular é o encurtamento adaptativo da unidade musculotendínea e outros tecidos moles que cruzam ou cercam a articulação, conforme Kisner e Colby (2005). A conseqüência desse processo é a perda de movimento da articulação em questão, quando ocorre apenas diminuição dessa movimentação ativa, ou seja, perda parcial do movimento denominado encurtamento muscular.

Segundo Starkey (2001), a diatermia por microondas (DMO) é uma modalidade de aquecimento profundo, que converte energia eletromagnética de alta freqüência em calor.

Kahn (2001) afirma que a radiação infravermelha aquece praticamente apenas a epiderme. Os tecidos mais profundos são aquecidos por condução, atingindo profundidades de até um centímetro. Os efeitos fisiológicos ocorrem quase que exclusivamente na parte superficial da pele.

De acordo com Low e Reed (2001), a termoterapia vem sendo utilizada antes do alongamento com o objetivo de potencializar os efeitos deste.

Conforme Lima et al. (2006), em algumas práticas clínicas, para se obter um maior ganho da flexibilidade usam-se técnicas de alongamento associadas ao calor. Espera-se que o aquecimento aumente o suprimento de sangue e a liberação do oxigênio da mioglobina e hemoglobina para os músculos. Estas mudanças preparam o corpo para as atividades físicas, por acelerar o metabolismo das fibras musculares e diminuir a resistência intramuscular, aumentando assim a variedade de movimento e a eficiência mecânica.

O objetivo deste estudo foi verificar a influência e as diferenças na utilização dos recursos térmicos de calor profundo e superficial na flexibilidade da musculatura isquiotibial.

\section{Metodologia}

Participaram deste estudo 48 estudantes (12 homens e 36 mulheres) com idade entre 18 e 59 anos, da Faculdade de Ciências da Saúde do Curso de Fisioterapia do UniCEUB (Centro Universitário de Brasília), mediante assinatura de um 
Termo de Esclarecimento e Livre Consentimento. O estudo foi encaminhado ao comitê de Ética e Pesquisa da instituição, onde foi aprovado, conforme o parecer de número 0037-07.

O critério de exclusão foi a partir de voluntários com quaisquer restrições à aplicação do calor superficial e profundo, com patologias associadas e que tenham no máximo 160 graus de encurtamento da musculatura isquiotibial (IQT).

Os participantes deste estudo foram distribuídos de forma aleatória em três grupos distintos: grupo controle (GC), alongamento muscular passivo, grupo calor superficial - (GCS), infravermelho da marca Quark associado ao alongamento passivo e grupo calor profundo - (GCP), diatermia por microondas da marca KLD - Biossistemas Equipamentos Eletrônicos, LTDA associada ao alongamento. $\mathrm{O}$ estudo foi realizado no membro inferior direito.

Inicialmente, foi avaliada a angulação poplítea do isquiotibial na perna direita. O individuo foi posicionado em decúbito dorsal com flexão de quadril a $90^{\circ}$. Foi realizado extensão de joelho passivamente e movimento de dorsiflexão ativo para a avaliação do grau de encurtamento do músculo isquiotibial com o goniômetro universal da marca Carci, ângulos poplíteos menores que $160^{\circ}$ foram base para a determinação de encurtamento de isquiotibiais.

No grupo controle (GC), após a goniometria, os indivíduos foram submetidos a 4 séries de 30 segundos de alongamentos passivos, com 10 segundos de relaxamento, de acordo com Lima et al. (2006), com carga de 3 quilogramas (kg). Esse alongamento foi feito em uma maca com o individuo em decúbito ventral. $\mathrm{O}$ peso de $3 \mathrm{~kg}$ ficou suspenso na roldana localizada na parte inferior da maca e preso ao pé direito do individuo. A força exercida pelo peso provocou uma dorsiflexão, ou seja, o alongamento passivo dos isquiotibiais. No final do alongamento foi realizada a goniometria semelhante à inicial.

No grupo GCS, após a goniometria, o indivíduo foi submetido à aplicação de infravermelho por 10 minutos a uma distância de 40 centímetros e intensidade subjetiva (de acordo com o "feedback" do paciente que relatava uma sensação de calor agradável). Em seguida, foi realizado o alongamento semelhante ao grupo de controle e à goniometria novamente. 
No grupo GCP, após a realização da goniometria, o indivíduo foi submetido à aplicação de microondas a uma distância de 10 centímetros por 10 minutos e intensidade de $50 \mathrm{~Hz}$.

Para análise estatística dos resultados foi utilizado o teste t-student pareado, segundo Vieira (1980), considerando que o nível de significância adotado no estudo foi $\alpha=0,05$.

\section{Resultados}

Inicialmente, foram abordados 48 estudantes de fisioterapia e após a utilização dos critérios de exclusão (ângulo poplíteo direito menor ou igual a $160^{\circ}$ ) foram selecionados 19 voluntários (7 homens e 12 mulheres) para participar da pesquisa.

As medidas do ângulo poplíteo antes e depois da realização do alongamento isolado, alongamento associado ao calor superficial e alongamento associado ao calor profundo estão representadas, respectivamente, nas tabelas I, II e III.

Apesar da média dos ângulos poplíteos da goniometria se apresentarem antes menor do que goniometria depois no GC, com base no teste T ao nível de significância de 5\%, a terapia somente com alongamento parece não ter relevância no aumento deste ângulo, conforme tabela 1.

Tabela 1 - Avaliação do ângulo poplíteo antes e após o alongamento dos IQT

\begin{tabular}{cccc}
\hline Indivíduo & Idade & G. Antes & G. Depois \\
\hline GC1 & 22 & $160^{\circ}$ & $163^{\circ}$ \\
\hline GC2 & 19 & $158^{\circ}$ & $158^{\circ}$ \\
\hline GC3 & 37 & $160^{\circ}$ & $160^{\circ}$ \\
\hline GC4 & 20 & $160^{\circ}$ & $163^{\circ}$ \\
\hline GC5 & 20 & $160^{\circ}$ & $164^{\circ}$ \\
\hline GC6 & 34 & $160^{\circ}$ & $168^{\circ}$ \\
\hline
\end{tabular}


De acordo com a análise estatística, ao utilizar o nível de significância de $5 \%$, o infravermelho demonstrou influência nos valores encontrados antes e depois da intervenção. A média encontrada na goniometria antes foi de $156,43^{\circ}$ e a média depois da intervenção foi de $167,86^{\circ}$, conforme a tabela 2 .

A análise estatística mostrou que a diatermia por microondas também tem influência relevante nos valores da goniometria antes e depois do recurso. As médias antes e após foram, respectivamente $154^{\circ}$ e $164^{\circ}$, conforme tabela 3 .

Tabela 2 - Avaliação do ângulo poplíteo antes e após intervenção de CS e alongamento nos IQT.

\begin{tabular}{cccc}
\hline Indivíduo & Idade & G. Antes & G. Depois \\
\hline GCS1 & 19 & $145^{\circ}$ & $158^{\circ}$ \\
\hline GCS2 & 18 & $160^{\circ}$ & $174^{\circ}$ \\
\hline GCS3 & 22 & $158^{\circ}$ & $166^{\circ}$ \\
\hline GCS4 & 19 & $157^{\circ}$ & $162^{\circ}$ \\
\hline GCS5 & 20 & $157^{\circ}$ & $170^{\circ}$ \\
\hline GCS6 & 21 & $160^{\circ}$ & $170^{\circ}$ \\
\hline GCS7 & 30 & $158^{\circ}$ & $175^{\circ}$ \\
\hline
\end{tabular}

\begin{tabular}{cccc}
\hline Indivíduo & Idade & G. Antes & G. Depois \\
\hline GCP1 & 25 & $149^{\circ}$ & $162^{\circ}$ \\
\hline GCP2 & 20 & $155^{\circ}$ & $168^{\circ}$ \\
\hline GCP3 & 19 & $156^{\circ}$ & $171^{\circ}$ \\
\hline GCP4 & 20 & $159^{\circ}$ & $165^{\circ}$ \\
\hline GCP5 & 36 & $145^{\circ}$ & $152^{\circ}$ \\
\hline GCP6 & 21 & $160^{\circ}$ & $166^{\circ}$ \\
\hline
\end{tabular}

Tabela 3 - Avaliação do ângulo poplíteo antes e após intervenção com diatermia por microondas e alongamento dos IQT. 


\section{Discussão}

Lima et al. (2006) utilizaram o exercício físico na esteira, como forma de aquecimento da musculatura isquiotibial, para verificar a sua eficácia no alongamento da mesma. De acordo com a análise estatística feita por este estudo, houve aumento significativo do alongamento entre o pré e póstreinamento no grupo treinamento e no grupo controle e retorno ao valor de origem (baseline) no $4^{\circ}$ dia, após o término do protocolo, também em ambos (aproximadamente 72 horas).

Em outro estudo realizado para analisar o efeito do calor do alongamento do músculo tríceps sural, Brucker et al. (2005) também não apresentaram diferença crônica de alongamento no calor profundo.

Neste estudo, não foi mensurada a manutenção do alongamento crônico, como nos artigos acima. Porém, a mensuração realizada referente da resposta aguda mostrou que a utilização da termoterapia associada ao alongamento influencia no aumento da amplitude articular. Este resultado corrobora com o estudo realizado por Peres et al. (2002) que mostra ser o alongamento com calor melhor do que o alongamento sozinho.

Draper et al. (2004) também chegaram à conclusão de que os resultados da flexibilidade do isquiotibial podem ser extremamente melhorados, quando o calor profundo é usado conjuntamente com alongamento prolongado.

Robertson et al. (2005) disseram que o calor profundo aumentou mais a angulação de dorsiflexão do que o calor superficial, ou somente o alongamento. O calor profundo, na ausência de alongamento, promove menor ganho de amplitude articular do que o calor superficial, sem alongamento. Porém a diferença não foi significativa estatisticamente.

Sabiamente, Brasileiro et al. (2007) disseram que sessões de alongamento, aplicadas diariamente, aumentaram significativamente a flexibilidade dos músculos isquiotibiais. Seus estudos não apresentaram efeitos crônicos, apenas agudos. Afirmaram que o resfriamento é melhor do que apenas o alongamento e também, melhor que alongamento com calor profundo. 


\section{Conclusão}

Observou-se um aumento nos dois recursos e no grupo controle. Porém, somente o alongamento não é suficiente para produzir um aumento agudo significante no ângulo poplíteo.

Concluímos que a aplicação da termoterapia profunda ou superficial auxilia no alongamento da musculatura isquiotibial, aumentando a amplitude de movimento. Sendo assim se recomenda o uso do calor superficial ou do calor profundo associado ao alongamento, principalmente para melhora de alterações biológicas relacionadas ao encurtamento muscular.

\section{Evaluation of the influence of infrared and of diathermy by microwaves associates to the passive stretching in shortening of the hamstring muscles}

\section{Abstract}

The diathermy by microwaves is a modality of profound heating, and the infrared radiation heats practically the epidermis. In some clinical practices, to obtain a larger gain of the flexibility, they use technic of stretching associates to the heat. This study had as a goal to verify the influence and the differences in the utilization of the thermal resources of profound and superficial heat in the flexibility of the musculature hamstring. Nineteen students of the Physiotherapy Course of the Centro Universitário de Brasília were distributed randomly in three distinct groups: GC (passive muscular stretching), GCS (infrared associate with passive stretching) and GCP (diathermy by microwaves associate to stretching). The results were obtained through the analysis of the popliteal angle before and after of each intervention, relating the resource with stretching. It concludes the application of thermoterapy deep or superficial it assists on the stretching of the musculature hamstring.

Keywords: Superficial thermotherapy. Deep thermotherapy. Stretching. Hamstring. 


\section{Referências}

BRASILEIRO, J. S; FARIA, A. F; QUEIROZ, L. L. Influência do resfriamento e do aquecimento local na flexibilidade dos músculos isquiotibiais. Revista Brasileira de Fisioterapia, São Carlos, v. 11, n. 1, 2007.

BRUCKER, J. B. et al. An 18-day stretching regimen, with or without pulsed, shortwave diathermy, and ankle dorsiflexion after 3 weeks Journal of Athletic Training, [S.1.], v. 40, n. 4, p. 276-280, 2005.

DRAPER, D. O. et al. Shortwave diathermy and prolonged stretching increase hamstring flexibility more than prolonged stretching alone. Journal of Orthopaedic \& Sports Physical Therapy, United States, [S.l.], v. 34, n. 1, p.13-20, 2004.

KHAN, J. Princípios e Prática de eletroterapia. 4a ed. São Paulo: Santos, 2001.

KYSNER, C.; COLBY, L. Exercício Terapêutico: fundamentos e técnicas. São Paulo: Manole, 2005.

LIMA, R. C. M. et al. Análise da durabilidade do efeito do alongamento muscular dos isquiotibiais em duas formas de intervenção. Acta Fisiatrica, São Paulo, [S.l.], v. 13, n. 1, p. 32-38, 2006.

LOW, J.; REED, A. Eletroterapia Explicada - princípios e prática. São Paulo: Manole, 2001.

PERES, S. E. et al. Pulsed shortwave diathermy and prolonged long-duration stretching increase dorsiflexion range of motion more than identical stretching without diathermy. Journal of Athletic Training, Dallas, [S.1.], v. 37, n. 1, p. 43-50, 2002 .

ROBERTSON, V. J; WARD, A.R; JUNG, P. The effect of heat on tissue extensibility: a comparison of deep and superficial heating. Archives of Physical Medicine and Rehabilitation, United States, v. 86, n. 4, p. 819-825, Apr, 2005.

STARKEY, C. Recurso terapêutico em fisioterapia. São Paulo: Manole, 2001. 